\title{
Research on the Modes of Targeted Pro-poor Tourism in the Internet Era
}

\author{
Chunyan Wang ${ }^{1, a}$ and Qinglan Luo ${ }^{1, b}$ \\ ${ }^{1}$ College of Business Administration, Jilin Engineering Normal University, Changchun City, China \\ a541012329@qq.com, bsunny203@126.com
}

Keywords: Pro-poor tourism; Intelligence system; O2O; Crowd-funding; Mode; Internet Era

\begin{abstract}
The development of the Internet Technology provides technical support for the development of pro-poor tourism. The mode of "Internet+ pro-poor tourism" is one of practice carriers of poverty governance in rural areas. By explicating the connotation system of targeted pro-poor tourism in Internet era, it emphasizes the necessity of developing pro-poor tourism in Internet era, and build up some new modes of targeted pro-poor tourism such as intelligent system, "O2O" mode, "Internet+ Crowd-funding", "Double micro" on the mobile internet and so on.
\end{abstract}

\section{Introduction}

At the end of 1990s, UK Department for International Development (DFID) put forward a new concept of Pro-poor Tourism (PPT), and pro-poor tourism has gradually become the research and practice focus of poverty alleviation at home and abroad [1]. Developing pro-poor tourism is an important way to solve the difficulties of industrial transformation and upgrading in poor areas and to implement targeted poverty alleviation and development.

Targeted poverty alleviation should reflect accuracy, applied to pro-poor tourism, which means that rural tourism poverty alleviation must ensure that the real poor population should get benefits from developing the tourism industry [2]. However, from the external institutional environment, it is difficult for the tourism industry to pay attention to and achieve the core objective of poverty alleviation which is to benefit the poor people and to create development opportunities for them. By studying the mode of pro-poor tourism in the contiguous poverty-stricken areas, someone believes that the existing mode of pro-poor tourism has the problems of lacking overall consideration for poverty alleviation goals and other issues [3]. From the internal factors of the poor population, the lack of human capital, social capital and financial capital has seriously hindered the effective participation of the poor in tourism development and management activities. Due to lack the knowledge, health and other human capital, the poor population are often excluded from the main beneficiaries of rural tourism [4]. Owing to the restriction of funds, knowledge, technology, the poor people are rejected from the development of rural tourism [5].

Although there are many difficulties in targeted pro-poor tourism, the development of Internet brings new opportunities for rural tourism. Internet will open up the information connection between poor rural areas and outside, to solve the problem of information asymmetry. By combining the Internet, e-commerce and targeted poor alleviation in poverty area, the original ecological tourism products from the poor mountainous areas will be introduced to outside the country and the world, to attract consumers to the poor area for enjoying the beautiful rural sightseeing and experiencing the original ecological farming culture. With the help of Internet tools, it can reduce the transaction and face consumers directly, and realize the targeted poverty alleviation through intelligence.

\section{Connotation System of Targeted Pro-poor Tourism in Internet Era}

With the development of social economy, China is to enter integration times the e-commerce and Internet. "Internet +" mainly refers to the Internet as a carrier of real action in a big data era, with the help of external network information technology (APP, mobile Internet, cloud computing, big data technology etc.), to achieve the comprehensive effect for benefiting the people. The final application of Internet should match the development demand of economy and social life. Thus, the "Internet +" not 
only simply put the Internet into the development process of other industries, its core lies in the integration of Internet and the development of the industry, in order to achieve "integration". In other words, it makes use of the convenient and quick characteristics of the Internet to combine it with the economy and industry to promote the growth of the real economy. By combing the concept of "Internet + ", it can be found that the theoretical core of "Internet + " is to achieve cross-border diversified industrial integration and transformation, to integrate the virtual Internet economy with the real world economy, to make endogenous development and external integration of information technology [6].

Pro-poor tourism provides opportunities and rights for the development of poor villages and poor people. As a related industry, tourism refers to many activities such as lodging, traveling, eating, shopping and entertainment and so on. From the macro level, by developing tourism industry to release "Agglomeration economy" and "Trickle-down effect", it can promote community economy continued steady growth, as far as possible to narrow the income gap between the communities [7]. In the "Internet $+"$ era, when the "targeted pro-poor tourism" and "Internet + " are embedded and combined, the innovation model of "Targeted pro-poor tourism in Internet era", which has become the core of national poverty governance to promote the work of the carrier. With the technological advantages of the Internet to promote the precision of poverty alleviation in China' pro-poor tourism, it forms a poor governance system with Chinese characteristics, is an important manifestation of national governance ability. The widespread promotion and application of Internet technology in pro-poor tourism projects, which will help to make the tourism anti-poverty project precise, professional and efficient development in the process of policy landing. By using the Internet path of rural tourism precise poverty, it will increase between the poor and the government timely exchange of information, so that poor households can produce and trade according to the tourism market demands, to ensure the accuracy of the information, is an important and reliable way of information dissemination [8]. In addition, targeted pro-poor tourism with Internet also can reduce information asymmetry, reduce transaction costs, and improve the effectiveness of pro-poor tourism projects.

\section{The Modes of Targeted Pro-poor Tourism in Internet Era}

Intelligence System of Targeted Pro-poor Tourism in Internet Era. The patency of the communication network is a necessary channel for poor areas with the outside world, mutual exchange of needed products for the exchange of information, infrastructure construction and to realize the precise poverty "Internet plus" model must be established in the communication network, so as to achieve poverty alleviation "global communications information network". The precision of the pro poor tourism relies on the "Internet plus rural tourism production, in order to form a fusion of agriculture and farmers, and modern information technology in depth, make advanced information industry to help the poor and the tourism market demand extensive docking [5]. As a high speed communication network carrier, broadband optical fiber is an important carrier to help precision poverty alleviation. Therefore, we should promote the construction of optical fiber network into the village. Bring thousands of households in poor areas, so that people at home one can learn about the outside information and change, makes timely adjustments to the development of modern agriculture in accordance with the needs of the tourism market, such as sightseeing agriculture, farm tourism and other projects. At the same time, poor households can use the Internet to advertise their travel products, e-commerce, and build public numbers. On the other hand, the poor families can understand the government's poverty alleviation policy in a timely manner, so as to achieve timely feedback of information and adjust their goals and plans at any time, so as to achieve dynamic coordination. In a word, advanced network technology and high coverage network is an important part of precision poverty alleviation, which is helpful to increase the scientific and informational level of poverty alleviation work in tourism (Fig. 1). 


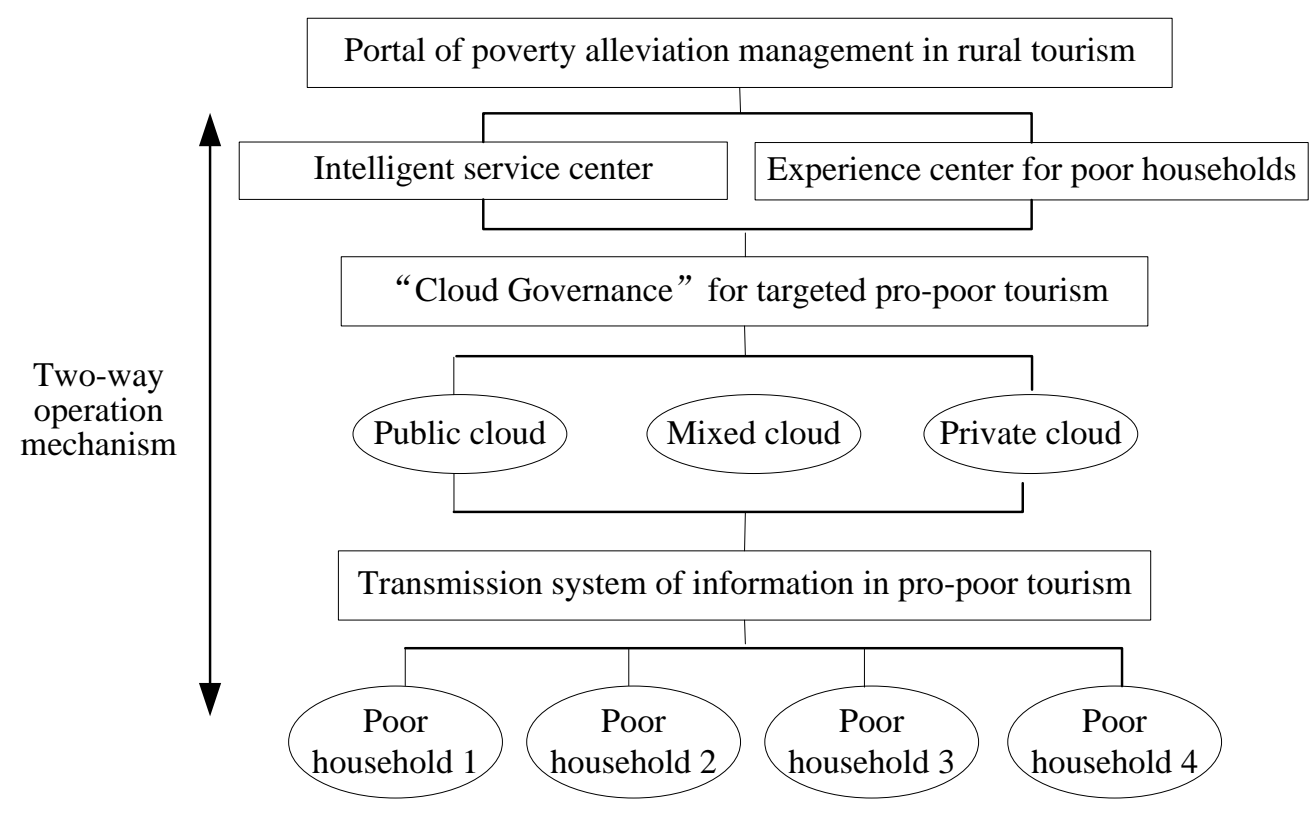

Figure 1. Intelligence system of targeted pro-poor tourism

The Mode of O2O from Online Retailers. At present, the proportion of e-commerce in the social economy is becoming larger and larger, and the combination of rural tourism and electricity providers provides us with a new idea. We should make use of the tourism resources and advantages of the poor areas, develop local characteristic tourism products according to local conditions, and actively establish connections between the poor households and the e-commerce platform. The Internet and e-commerce extensive cooperation, the rural tourism products production and marketing depth combine to form a complete chain, and combined with the entity platform, the formation of online platforms and line platform combining $\mathrm{O} 2 \mathrm{O}$ mode (Fig. 2). With the network information platform as the carrier, the rural tourism product information, supply situation, product quality, market price, sales situation, customer satisfaction and other information are gathered into the network information platform. Farmers can refer to the information, timely understanding of the tourism market, and make a dynamic adjustment. At the same time, it can also improve efficiency and produce more tourism products which are in line with the high value-added tourism market. $\mathrm{O} 2 \mathrm{O}$ model can combine agriculture and tourism market better, and it is a new model worth researching and popularizing.

As consumer spending habits change, people are more likely to experience the whole process of consumption and feel the joy of participation. This provides new ideas for the promotion and publicity of rural tourism products. First of all, according to the change of consumption of consumers, the rural tourism products they are interested in updating on the network and micro platform, and electronic business enterprise, the product information to the website promotion. This producer can see the market price and the demand on the website, consumers can see the rural tourism product information and sales price, do the integration mode of rural tourism products production base, network information platform and market information. At the same time, this model brings together the information of the three, which is conducive to achieving win-win situation for each business entity, and is more conducive to providing a new way for poverty alleviation in precise tourism. It can effectively help poor areas to use their own advantages, resources to achieve income increase, to achieve a smooth way of poverty alleviation. 


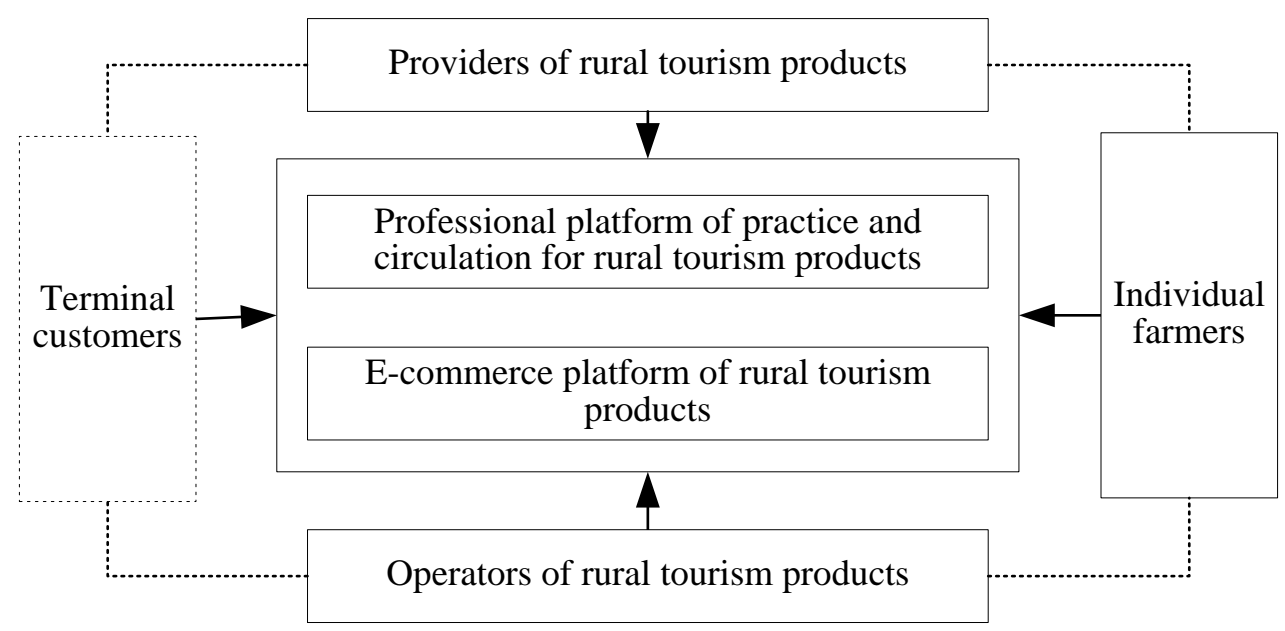

Figure 2. Mode of $\mathrm{O} 2 \mathrm{O}$ for rural tourism products

The Mode of Crowd-funding on the Internet. Crowd-funding is mainly refers to the "Internet +" background through the "group purchase + pre order form, for a wide range of internet groups to achieve the fund-raising mode of action. It can be seen that all chips model has both the Internet and social networking services (SNS) and other means of dissemination of reality [8]. One is "Crowd-funding" mode. The technical characteristics of inclusive Internet plus "era, technology advantage makes any client can use the Internet to buy their products, the rural tourism products is no exception. High quality tourism products in poor areas can be realized by "all kinds of chips", while consumers can purchase "poor peasant households" products. Thus, consumers with poor farmers so as to construct the community through the network technology and equipment Internet plus ", realize the coupling of the community relationship [9]. On the one hand, consumers to raise funds, funds will advance in poverty-stricken areas of farmers, thereby reducing the farmers tourism product development initial investment economic pressure; technical means on the other hand with the help of Internet plus to establish network community relations, in order to facilitate the parties to contact each other, sharing "Internet plus" inclusive results. To achieve accurate poverty alleviation practice effect [10]. Two is "order type" production mode. By the advantage of information technology "Internet plus", the network orders for the intermediate information transfer vector, to achieve precise poverty alleviation of rural tourism products. But because of the differences in consumer demand for products, it should be satisfy consumer demand for tourism products to provide practical service standards, and the introduction of different types of rural tourism products to meet consumer demand for tourism.

The Mode of "Double Micro" Pro-poor Tourism on the Mobile Internet. With the rapid development of mobile Internet, communications infrastructure facilities in rural poor areas continue to improve, the wireless network in many rural areas have basically achieved full coverage, for the majority of poor households through mobile Internet (Mobile Commerce) tourism product (service) marketing and promotion provided convenient conditions. After professional e-commerce training, the large number of poor farmers can use micro-blog and WeChat for operating and promoting the agricultural products, rural tourism destination, farmhouse resorts.

Micro-blog, anytime, anywhere direct seeding, breeding, production, WeChat can dry out products and services at any time, whether it is pictures or video, you can share the fruits of labor in real-time. In addition, but also through the "double" products and services in sales, micro-blog and WeChat on the sale of rural tourism products have become an essential skill of modern rural tourism product marketing, especially the use of WeChat public number (subscription number and service number), the WeChat matrix, to better promote the original brand in poor areas the. As for the original eco-agricultural tourism it needs to develop mobile phone APP, and build development program based on WeChat platform. Through mobile phone mobile APP program, increase the tourism products in poor areas, brand promotion and product sales at the same time, gradually improve the soft power and market influence in poor areas. 


\section{Conclusion}

Make full use of the "Internet plus", in the poor areas, poverty alleviation center construction of intelligent information system of rural tourism, the realization of online booking, payment, electronic authentication and unified management. It can use the cloud computing, Internet of things, mobile Internet and other new technologies to achieve rural tourism and traffic, public security, medical and other interoperability and overall linkage. Improve the level of tourist information service [11], provide tourists with wireless Internet service, and realize the intelligent push service of rural tourism information. The use of networking, cloud computing, mobile Internet, 3G, RFID positioning and other advanced technology, integration of food housing traveling, entertainment and purchasing all resources in the regional center of "real space" has launched the purchase of agricultural products, rural tourism, catering, accommodation and other farm discounts in one of the rural tourism integration service system [12]. Through the combination of virtual and reality, it can integrate the rural tourism resources in poor areas, to achieve the transformation of traditional rural tourism to the wisdom of rural tourism.

\section{Acknowledgements}

This paper is sponsored by project fund from Jilin Planning Office of Philosophy and Social Science (Project Title: Research on current situation and development countermeasures of Pro-poor tourism in Jilin province; Contract NO. 2016B101). In addition, it is also sponsored by the grant from the Research and Development Project of Jilin Engineering Normal University.

\section{References}

[1] H.Q. Li, L.C. Hou, S.W. Yang and J.R. Brent Ritchie: Human Geography, Vol. 30 (2015) No.1, p.26-32.

[2] Y.L. Wang: Reform of Economic System, Vol. 25 (2007) No.4, p.92-96.

[3] G.Q. Huang: Seeker, Vol. 33 (2013) No.5, p.253-255.

[4] J.H. Xiao and J.N. Xiao: Social Scientist, Vol. 29 (2014) No.1, p.76-80.

[5] C.W. Huang, X.L. Wang and L.P. Xu: Journal of Agrotechnical Economics, Vol. 29 (2010) No.8, P.4-11.

[6] C.F. Tong and H. Zhang: World Agriculture, Vol. 38 (2016) No.8, p.50-56.

[7] A. Blake, J.S. Arbache, M.T. Sinclair, et al.: Annals of Tourism Research, Vol. 35 (2008) No.1, p.107-126.

[8] J.X. Li: Issues in Agricultural Economy, Vol. 37 (2016) No.8, p.23-27.

[9] R. Butler, R. Curran and K.D. O'Gorman: International Journal of Tourism Research, Vol. 15 (2013) No.5, p.443-457.

[10] V.D.V.R. Duim and J.D.A.D. Caalders: Current Issues in Tourism, Vol. 11 (2012) No.2, p.109-125.

[11] O. A. Akyeampong: Journal of Sustainable Tourism, Vol. 19 (2011) No.2, p.197-213.

[12] A,M. Trau: Tourism Planning \& Development, Vol. 9 (2012) No.2, p.149-164. 